4. Aaltonen KJ, Joensuu JT, Pirila $L$, et al. Drug survival on tumour necrosis factor inhibitors in patients with rheumatoid arthritis in Finland. Scand J Rheumatol. 2016;46(5):359-363.

5. Smolen JS, Landewe RBM, Bijlsma JWJ, et al. EULAR recommendations for the management of rheumatoid arthritis with synthetic and biological disease-modifying antirheumatic drugs: 2019 update. Ann Rheum Dis. 2020;79(6):685-699.

6. Fraenkel L, Bathon JM, England $B R$, et al. 2021 American College of Rheumatology Guideline for the Treatment of Rheumatoid Arthritis. Arthritis Care Res (Hoboken). 2021;73(7):924-939.
7. Berger N, Peter M, DeClercq J, Choi L, Zuckerman AD. Rheumatoid arthritis medication adherence in a health system specialty pharmacy. The American journal of managed care. 2020;26(12):e380-e387.

8. Rashid N, Lin AT, Aranda G, Jr., et al. Rates, factors, reasons, and economic impact associated with switching in rheumatoid arthritis patients newly initiated on biologic disease modifying antirheumatic drugs in an integrated healthcare system. Journal of medical economics. 2016;19(6):568-575.

\title{
KẾT QUẢ HÓA TRI PHÁC Đồ CHỨA PLATIN TRONG ĐIỀU TRI UNG THƯ BIỂU MÔ TUYẾN VÚ Có Bộ BA ÂM TÍNH TÁI PHÁT DI CĂN
}

\section{TÓM TẮT.}

Mục tiêu: Đánh giá kết quả điều trị bằng phác đồ hóa chất chứa platin trên bệnh nhân ung thư biểu mô tuyến vú có bộ ba âm tính (BBAT) tái phát di căn. Đối tượng và phương pháp nghiên cứu: Nghiên cứu mồ tả hồi cứu trên 56 bệnh nhân được chẩn đoán ung thư biểu mô tuyến vú có BBAT tái phát hoăc di căn. Kết quả: Đặc điểm nhóm nghiên cứu: Tuổi trung bình ở thời điểm tái phát, di căn là $49,2 \pm 12,2$. Thời gian sống thêm không bệnh (DFS) là 16,3 tháng. Trong 56 bệnh nhân điều trị bằng phác đồ chứa platin, có 20 bệnh nhân được điêuu trị bằng phác đồ paclitaxel carboplatin chiểm 35,7\%, 36 bệnh nhân được điều trị bằng phác đồ gemcitabine - carboplatin chiểm 64,3\%. Tỷ lệ đáp ứng chung của phác đồ là $58,9 \%$; trong đó $10,7 \%$ đáp ứng hoàn toàn, đáp ứng 1 phân là 48,2\%, bệnh giữ nguyên là $12,5 \%$, bệnh tiến triển là $28,6 \%$. Tỷ lệ đáp ứng ở nhóm bệnh nhân điều trị phác đồ bước 1 là 67,5\%, cao hơn so với nhóm bệnh nhân điều ở bước 2 là $37,5 \%$, sự khác biệt có ý nghĩa thống kê với $p=0,039$. Trung vị thởi gian sống thêm bệnh không tiến triển là 7 tháng. Độc tính của phác đồ thường gặp chủ yếu là độ 1,2 . Các độc tính thường gặp là hạ bạch câu hạt $(63,5 \%)$, hạ huyết sắc tố $(50 \%)$, hạ tiểu cầu $(26,8 \%)$, rụng tóc $(46,4 \%)$, nôn và buồn nôn $(51,7 \%)$. Kết luấn: Hóa trị phác đồ chứa platin được chứng minh có hiệu quả, độc tính của phác đồ chấp nhận được trên nhóm bệnh nhân UTV BBAT tái phát di căn, do vậy có thể áp dung trong điều trị trong điều kiện hiện nay ở nước ta hiền nay.

Tư khóa: Ung thư vú bộ ba âm tính, platin, thời gian sống thêm bệnh không tiến triển.

\footnotetext{
${ }^{1}$ Trường Đại học Y Hà Nội

²Bênh viên $K$

Chịu trách nhiệm chính: Bùi Thành Lập

Email: lapxuanthu.bhn@gmail.com

Ngày nhận bài: 11.8.2021

Ngày phản biện khoa học: 7.10.2021

Ngày duyệt bài: 15.10.2021
}

\section{SUMMARY \\ THE EFFICACY OF PLATIN-BASE CHEMOTHERAPY OF RECURRENT OR METASTATIC IN THE \\ TRIPLE NEGATIVE BREAST CANCER}

Objectives: To evaluate the efficacy of platinbase chemotherapy of metastatic of triple negative breast cancer. Patients and methods: Retrospective, descriptive study on 56 patients with recurrent or metastatic of triple negative breast cancer, were treated with platin-base chemotherapy regiment at National Cancer Hospital. Results: The mean age was 49,2 $\pm 12,2$. Mean disease-free survival time (DFS) was 16,3 months. The overall response rate (ORR) of the regimen was $58,9 \%$. The complete response rate was $10,7 \%$, the partial response rate was $48,2 \%, 12,5 \%$ of the patients were stable and $28,6 \%$ of the patients had progressive disease. ORR in first-line therapy was better than that in the secondline of treatment (ORR: $67,5 \%$ vs $37,5 \% ; p=0,039$ ). The median progression-free survival was 7,0 months. The common toxicity was neutropenia $(63,5 \%)$, anemia (50\%), 26,8\% for thrombocytopenia, hair loss $(46,4 \%)$, and $51,7 \%$ for vomiting and nausea. Conclusions: Platinum-based chemotherapy is effective in high response rates and progression-free survival for patients with recurrent or metastatic of triple negative breast cancer. However, it is necessary to evaluate and closely monitor the toxicity of the regimen during treatment

Keyword: Triple negative breast cancer, platin, progression-free survival.

\section{I. ĐĂT VẤN ĐỀ}

Theo GLOBOCAN 2020, ung thư vú (UTV) là loại ung thư có tỷ lệ mắc nhiếu nhất trên toàn thế giới và là nguyên nhân gây tử vong thứ 5 sau ung thư phổi, đại trực tràng, gan và dạ dày ở cả 2 giới. Riêng ở nữ giới, UTV chiếm $1 / 4$ số trường hợp ung thư mới mắc và chiếm $1 / 6$ tổng số các ca tử vong do ung thư. Tại Việt Nam, tỷ lệ 
mắc mới UTV chuẩn theo tuổi là $34,2 / 100.000$ dân, đứng đầu trong các loại ung thư phổ biến ở nữ với 21.555 trường hợp và đứng thứ 4 trong số các nguyên nhân tử vong do ung thư nữ giới với 9.345 trường hợp, đứng sau ung thư gan, phổi và dạ dày [1].

UTV bộ ba âm tính được xác định bởi thu thể nội tiết estrogen $(E R) /$ progesterone $(P R)$ và yếu tố phát triển biểu bì Her-2 âm tính, chiếm khoảng 12-20\% trên tổng số các loại UTV. Kiểu hình này có tiên lượng xấu với đặc điểm riêng biệt về yếu tố nguy cớ, đặc điểm phân tử, biểu hiện lâm sàng, mô bệnh học, đáp ứng điều trị, di căn và tái phát [2], [3]. UTV có bộ ba âm tính có tỷ lê tái phát di căn rất cao trong những năm đâu tiên sau điều trị đặc biệt cao điểm trong 3 năm đầu [4].

Trên thế giới, nhiều nghiên cứu điêu trị UTV BBAT tái phát di căn bằng phác đồ hóa chất có chứa platin cho thấy hiệu quả điều trị cao hơn so với phác đồ không chứa platin [2], [5]. Zhang và CS (2015) đã nghiên cứu trên 364 BN UTV BBAT di căn điêu trị hóa chất bước 1 trong đó có 218 $\mathrm{BN}$ được điều trị bằng phác đồ hóa chất có chứa platin và $146 \mathrm{BN}$ điều trị bằng phác đồ không chứa platin. Kết quả cho thây nhóm BN điều trị bằng platin có thời gian sống thêm bệnh không tiến triển (PFS) dài hơn so với nhóm BN còn lai (7.8 tháng so với 4.9 tháng, $p<0.001$ ). Tỉ lệ đáp ứng toàn bộ ở nhóm được điều trị bước 1 bằng platin cũng cao hơn so với nhóm không dùng platin (57,3\% so với 32,9\%) [5].

Hiện nay, tại Việt Nam cũng có nhiều bệnh nhân UTV BBAT tái phát di căn được điều trị bằng phác đồ có chứa platin nhưng chưa có tác giả nào nghiên cứu đánh giá hiệu quả điều trị của phác đồ trên. Vì vậy, chúng tôi tiến hành nghiên cứu: "Đánh giá kêt quả điều trị bằng phác đồ hóa chất chứa platin trên bệnh nhân ung thư biêu mô tuyến vú có bộ ba âm tính tái phát di căn"

\section{II. ĐỐI TƯợNG VÀ PHƯƠNG PHÁP NGHIÊN CỨU}

1.Đối tượng nghiên cứu. Bệnh nhân nữ được chẩn đoán xác định là ung thư vú có bộ ba thụ thể $E R, P R$ và Her-2 âm tính tái phát di căn, được điều trị bằng phác đồ hóa chất chứa platin từ 01/2014 tới 03/2021.

\subsection{Tiêu chuẩn lứa chon:}

- Bênh nhân nữ được chẩn đoán xác định ung thư biếu mô tuyến vú bằng xét nghiệm mô bệnh học.

- Có kết quả nhuộm hóa mô miễn dịch đánh giá thụ thể nội tiết $E R, P R$ và Her-2 âm tính của tổn thương u ban đâu hay tổn thương tái phát di căn.
- Đã được điều trị triệt căn cho giai đoạn tại chỗ, tại vùng bằng các các phương pháp phấu thuật, hoá chất, xạ trị, nội tiết, điều trị đích theo chỉ định hoặc ung thư vú giai đoạn IV đã hoặc chưa điều trị hoá chất, không có chỉ định điều trị tại chỗ tại vùng.

- Chẩn đoán tái phát di căn bằng chẩn đoán hình ảnh hoă̆c tế bào học hoặc mô bệnh học.

- Được điều trị phác đồ hóa chất gemcitabine - carboplatin hoặc paclitaxel - carboplatin ít nhất 3 chu kỳ.

- Có tổn thương đánh giá được đáp ứng theo tiêu chuẩn RECIST.

- Chỉ số toàn trạng ECOG $\leq 2$.

- Chức năng gan thâan tủy xương trong giới hạn cho phép điều trị hóa chất

\subsection{Tiêu chuẩn loại trừ:}

- Bệnh nhân di căn não.

- Bểnh nhân đang mắc các bệnh cấp và mạn tính trẩm trong khác.

- Bệnh nhân dị ứng với thuốc.

- Bệnh nhân ngừng điều trị thuốc không phải vì lý do bệnh tiến triển, độc tính, kết thúc nghiên cứu.

- Bệnh nhân có ung thư nguyên phát tại cơ quan khác.

\section{Phương pháp nghiên cứu}

2.1. Thiết kế nghiên cứu. Nghiên cứu mô tả hồi cứu

2.2. Cỡ mẫu nghiên cứu. Áp dụng công thức tính cỡ mẫu cho việc ước tính một tỷ lệ:

$$
n=Z_{1-\propto / 2}^{2} \frac{p \cdot(1-p)}{(p \cdot \varepsilon)^{2}}
$$

Trong đó: n: cõ̃ mẫu tối thiểu cần đạt được trong nghiên cứu

Z: hệ số tin cậy, với $a=0,05$ tra bảng $Z=1,96$

$\mathrm{p}$ : tỷ lệ đáp ứng của nghiên cứu tương tự trước đó, $\mathrm{p}=0,57[5]$.

ع: giá trị tương đối, thường chọn trong khoảng $(0,1-0,4)$. Chọn $\varepsilon=0,25$

Ước tính cõ mẫu tối thiểu trong nghiên cứu cần phải đạt được là 46 bệnh nhân.

2.3. Phác đồ điêu trị: Bệnh nhân sau khi được chẩn đoán tái phát di cắn có đầy đủ các tiêu chuẩn trên được điều trị bằng hóa chất theo 1 trong 2 phác đồ:

- Phác đồ paclitaxel-carboplatin, chu kỳ 3 tuần.

Paclitaxel $175 \mathrm{mg} / \mathrm{m}^{2}$ - carboplatin AUC 5-6. Nhắc lại mỗi đợt sau 21 ngày

- Phác đồ gemcitabine - carboplatin, chu kỳ 3 tuân.

Gemcitabine $1000 \mathrm{mg} / \mathrm{m}^{2}$ da truyền tînh mạch ngày 1 và 8 . Carboplatin AUC 5-6, truyền tĩnh mạch ngày 1 . Nhắc lại mỗi đợt sau 21 ngày.

Đánh giá độc tính của phác đồ: Độc tính trên huyết học và độc tính trên thần kinh ngoại 
biên (Theo NCI-CTCAE 5.0)

Đánh giá đáp ứng điêu trị: sau 3 chu kì, theo RECIST 1.1 [6] gồm: Đáp ứng hoàn toàn, Đáp ứng 1 phần, Bệnh ổn định, Bệnh tiến triển.

Đánh giá thời gian sống thêm bệnh không tiến triển (PFS): là khoảng thời gian từ lúc bệnh nhân bắt đầu được điều trị cho tới thời điểm xác định bệnh tiến triển hoặc bệnh nhân tử vong.

3. Đạo đức nghiên cứu: Nghiên cứu đã được thông qua tại Hội Đồng Đạo đức Bệnh viện K.

\section{KẾT QUẢ NGHIÊN CỨU}

1. Một số đặc điểm của đối tượng nghiên cứu. Kết quả cho thấy trong tổng số 56 bệnh nhân tham gia nghiên cứu, tuổi trung bình của các đối tượng nghiên cứu là 49,2, thấp nhất là 25 tuổi, cao nhất là 71 tuổi. Các bệnh nhân trong nghiên cứu phần lớn ở giai đoạn II và III tại thời điểm chẩn đoán ban đầu, chiếm $79,6 \%$, có 1 bệnh nhân nào ở giai đoạn I chiếm $1,8 \%$. Trong số 56 bệnh nhân có 16 bệnh nhân ở giai đoạn IV ngay từ lần chẩn đoán đầu tiên, chiếm 28,6\%. Trong nghiên cứu của chúng tôi, phần lớn các bệnh nhân thuộc thể ung thư biểu mô xâm nhập típ không đặc biệt (NST), chiếm 78,6\%, 5 bệnh nhân ung thư biểu mô biểu thuỳ xâm nhập chiếm 8,9. Trong số 40 bệnh nhân trong nhóm nghiên cứu được chẩn đoán bệnh ở giai đoạn tại chỗ, tại vùng sau khi điều trị triệt căn, thời gian xuất hiện tái phát di căn hay gặp là sau 2 năm đầu chiếm $82,5 \%$. Trung bình thời gian sống thêm không bệnh là 16,3 tháng, ngắn nhất là 3 tháng, dài nhất là 51 tháng. Các vị trí di căn thường gặp trong nghiên cứu của chúng tôi lần lượt là phổi, gan và xương chiếm tỉ lệ lần lượt là $48,2 \%, 28 \%$ và $25 \%$.

Trong 56 bệnh nhân được điều trị bằng phác đồ chứa platin, có 20 bệnh nhân được điêu trị bằng phác đồ paclitaxel - carboplatin chiếm 35,7\%, 36 bệnh nhân được điều trị bằng phác đồ gemcitabine - carboplatin chiếm 64,3\%. Có 40 bệnh nhân được điều trị phác đồ chứa platin bước 1 , chiếm 71,4 và 16 bệnh nhân nhận điều trị phác đồ chứa platin bước 2 , chiếm $28,6 \%$.

Bảng 1: Một số đặc điểm của đối tượng nghiên cứu

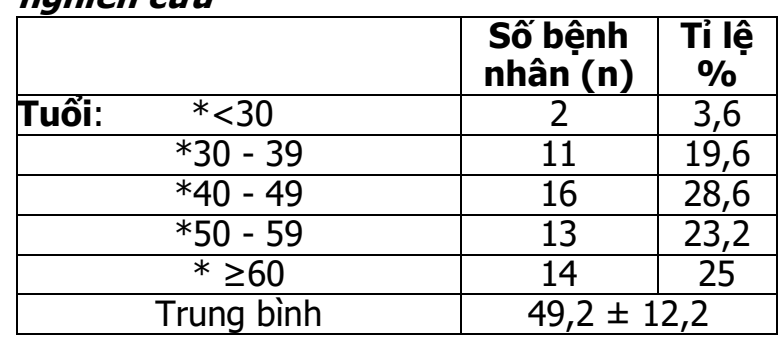

\begin{tabular}{|c|c|c|}
\hline \multicolumn{3}{|c|}{ Giai đoạn ban đâuu } \\
\hline *Giai đoạn I & 1 & 1,8 \\
\hline *Giai đoạn II & 20 & 35,7 \\
\hline *Giai đoạn III & 19 & 33,9 \\
\hline *Giai đoạn IV & 16 & 28,6 \\
\hline \multicolumn{3}{|c|}{ Mô bệnh học } \\
\hline *UTBM xâm nhập NST & 44 & 78,6 \\
\hline *UTBM tiếu thùy xầm nhập & 5 & 8,9 \\
\hline *UTBM thế dị sản & 3 & 5,4 \\
\hline *UTBM thê tủy & 2 & 3,6 \\
\hline *Khác ${ }^{1}$ & 2 & 3,6 \\
\hline Độ mô học : *Độ 1 & 1 & 2,4 \\
\hline *Độ 2 & 26 & 63,4 \\
\hline *Độ 3 & 14 & 34,1 \\
\hline \multicolumn{3}{|c|}{ Tình trạng Ki-67 } \\
\hline$* \mathrm{Ki}-67<20$ & 10 & 17,9 \\
\hline *Ki-67 $\geq 20 \%$ & 46 & 82,1 \\
\hline \multicolumn{3}{|c|}{ Vị trí tái phát di căn } \\
\hline *Tại chô tại vùng & 11 & 19,6 \\
\hline *Hạch trung thất, ô bụng & 12 & 21,4 \\
\hline *Xương & 14 & 25,0 \\
\hline *Gan & 16 & 28,0 \\
\hline *Phối & 27 & 48,2 \\
\hline *Khác ${ }^{3}$ & 4 & 7,1 \\
\hline \multicolumn{3}{|c|}{ Di căn tạng } \\
\hline *Không di căn tạng & 18 & 32,1 \\
\hline *Di căn tạng (gan hoặc phối) & 34 & 60,7 \\
\hline \multicolumn{3}{|l|}{ CA 15-3 } \\
\hline *Trong giới hạn bình thường & 29 & 51,8 \\
\hline *Tăng cao hơn bình thường & 27 & 48,2 \\
\hline \multicolumn{3}{|c|}{ Phác đồ điều trị tái phát di căn } \\
\hline *Paclitaxel - carboplatin & 20 & 35,7 \\
\hline *Gemcitabine - carboplatin & 36 & 64,3 \\
\hline \multicolumn{3}{|c|}{ Điêu trị hóa chất bước } \\
\hline *Bước 1 & 40 & 71,4 \\
\hline *Bướ & 16 & 28,6 \\
\hline
\end{tabular}

\section{Chú thích:}

${ }^{1}$ Gồm 1 bệnh nhân ung thư biểu mô thể nhẫn và 1 bệnh nhân ung thư biểu mô thể vi nhú.

${ }^{2}$ Trong số 41 bệnh nhân UTBM xâm nhập NST

3 Gồm 1 BN di căn hạch thượng đòn đối bên, 1 di căn hạch chậu, 1 BN di căn màng phổi

4. Đáp ứng với điều trị và 1 số yếu tố liên quan. Trong số 56 bệnh nhân nghiên cứu, sau 3 đợt điều trị, có 30 bệnh nhân ghi nhận đáp ứng, chiếm $53,6 \%$, trong đó không có bệnh nhân nào đáp ứng hoàn toàn. Tỷ lệ đáp ứng chung của phác đồ là $58,9 \%$, trong đó tỷ lệ đáp ứng hoàn toàn là $10,7 \%$. Có $12,5 \%$ bệnh nhân đạt bệnh giữ nguyên, như vậy lợi ích lâm sàng đạt $71,4 \%$. Có 16 bệnh nhân tiến triển ngay sau 3 chu kỳ điều trị chiếm $28,6 \%$. Tỷ lệ đáp ứng ở nhóm bệnh nhân điêu trị phác đồ bước 1 là 67,5\%, cao hơn so với nhóm bệnh nhân điều trị 
phác đồ này ở bước 2 là 37,5\%, sự khác biệt có ý nghĩa thống kê với $p=0,039$. Nhìn chung, đáp ứng của phác đồ phần lớn đạt được sau 3-6 đợt điều trị. Không có sự khác nhau giữa tỉ lệ đáp ứng điều trị với cá yếu tố liên quan như thể mô bệnh học, độ mô học, mức độ độ bộc lộ Ki-67, vị trí di căn hay việc lựa chọn phác đồ điều trị gemcitabine - carboplatin hay paclitaxel carboplatin $(p>0,05)$.

Bảng 2: Mối liên quan giữa tỉ lệ đáp ứng với các yêu tố liên quan

\begin{tabular}{|c|c|c|c|c|c|}
\hline \multirow[t]{2}{*}{ 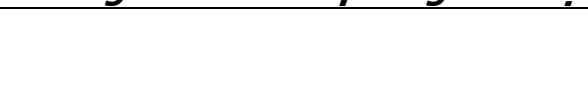 } & \multicolumn{2}{|c|}{ Bệnh đáp ứng } & \multicolumn{2}{|c|}{ Bệnh không đáp ứng } & \multirow[b]{2}{*}{$\mathbf{p}$} \\
\hline & n1 & $\%$ & n2 & $\%$ & \\
\hline Độ mô học: *Độ 1 & 1 & 100 & 0 & 0 & \multirow{3}{*}{$p=0,097$} \\
\hline *ंĐộ 2 & 19 & 65,4 & 7 & 34,6 & \\
\hline *Đố 3 & 5 & 35,7 & 9 & 64,3 & \\
\hline Tống & 33 & 56,1 & 23 & 43,9 & \\
\hline \multicolumn{6}{|l|}{ Mô bệnh học } \\
\hline UTBM xâm nhập NST & 23 & 56,1 & 18 & 43,9 & \\
\hline UTBM tiếu thùy xâm nhập & 4 & 66,7 & 2 & 33,3 & $p=0,828$ \\
\hline Loại khác & 6 & 66,7 & 3 & 33,3 & \\
\hline Tống & 39 & 58,9 & 17 & 44,1 & \\
\hline Tình trạng Ki-67: *Ki-67 < 20\% & 7 & 70 & 3 & 30 & $p=0.500$ \\
\hline$*_{\mathrm{Ki}-67} \geq 20 \%$ & 26 & 56,5 & 20 & 43,5 & \\
\hline Tống & 33 & 58,9 & 23 & 41,1 & \\
\hline \multicolumn{6}{|l|}{ Tình trạng di căn tạng } \\
\hline *Có di cắn tạng & 22 & 57,9 & 16 & 42,2 & $p=1,000$ \\
\hline *Không di căn tạng & 11 & 61,1 & 7 & 38,9 & \\
\hline Tổng & 39 & 58,9 & 17 & 41,1 & \\
\hline \multicolumn{6}{|l|}{ Phác đồ điêuu trị } \\
\hline *Paclitaxel - carboplatin & 14 & 70 & 6 & 30 & \\
\hline *Gemcitabine - carboplatin & 19 & 52,8 & 17 & 47,2 & $p=0,209$ \\
\hline Tống & 33 & 58,9 & 23 & 41,1 & \\
\hline Điều trị bước: *Bước 1 & 14 & 70 & 6 & 30 & \\
\hline *Bước 2 & 19 & 52,8 & 17 & 47,2 & $p=0,209$ \\
\hline Tống & 33 & 58,9 & 23 & 41,1 & \\
\hline
\end{tabular}

5.Thời gian sống thêm không tiến triển của bệnh nhân. Thời gian trung bình sống thêm không tiến triển là 6,97 tháng. Tối thiểu là 3 tháng, tối đa là 18 tháng. Trung vị sống thêm bệnh không tiến triển là 7,0 $\pm 0,5$ tháng. Tỷ lệ sống thêm không bệnh tiến triển tại thời điểm 3 tháng và 6 tháng và 9 tháng lần lượt là: $83,9 \%$, $58,8 \%$ và $5,5 \%$

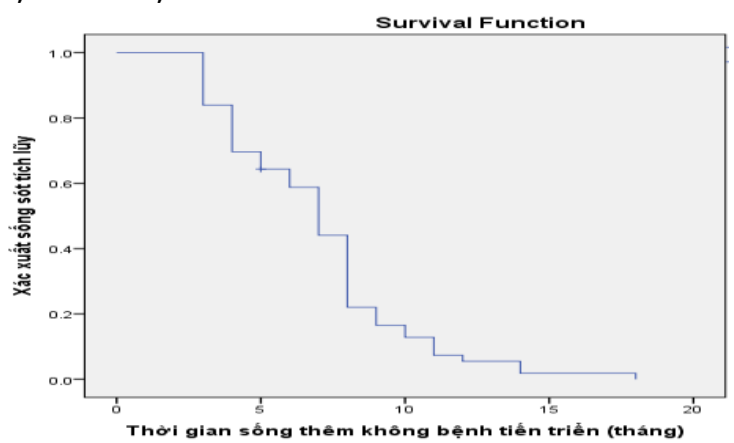

Biểu đồ 3.7. Thời gian sống thêm không bệnh tiến triển (PFS)
Bảng 2: Môi liên quan giữa PFS với các yếu tố liên quan

\begin{tabular}{|c|c|c|c|}
\hline & $\begin{array}{c}\text { Trung vị } \\
\text { (tháng) }\end{array}$ & $\begin{array}{c}\text { 95\% } \\
\text { khoảng tin } \\
\text { cậy(tháng) }\end{array}$ & p \\
\hline \multicolumn{4}{|c|}{ Phác đồ hóa chất } \\
\hline $\begin{array}{c}\text { *Paclitaxel - } \\
\text { carboplatin }\end{array}$ & 8 & $7,4-8,6$ & 0,154 \\
\hline $\begin{array}{c}\text { *Gemcitabine } \\
\text { - carboplatin }\end{array}$ & 6 & $4,4-7,6$ & \\
\hline \multicolumn{4}{|c|}{ Điêuu trị bước } \\
\hline *Bước 1 & 7 & $6,3-7,7$ & 0,746 \\
\hline *Bước 2 & 4 & $2,1-5,9$ & \\
\hline \multicolumn{4}{|c|}{ Vị trí di căn } \\
\hline $\begin{array}{c}\text { *Không di căn } \\
\text { tạng }\end{array}$ & 8 & $6,9-9,1$ & 0,976 \\
\hline $\begin{array}{c}\text { *Có di căn } \\
\text { tạng }\end{array}$ & 7 & $6,0-8,0$ & \\
\hline
\end{tabular}

4. Độc tính. Độc tính của phác đồ thường gặp chủ yếu là độ 1, 2. Các độc tính thường gặp là hạ bach cầu hạt $(63,5 \%)$, hạ huyết sắc tố $(50 \%)$, hạ tiểu cầu $(26,8 \%)$, rụng tóc $(46,4 \%)$, nôn và buồn nôn $(51,7 \%)$ 


\section{BÀN LUÂN}

Kết quả của chúng tôi cho thấy tỷ lê đáp ứng chung của phác đồ là $58,9 \%$, trong đó tỷ lệ đáp ứng hoàn toàn là $10,7 \%$, tỷ lệ đáp ứng ở nhóm bệnh nhân điều trị phác đồ bước 1 và bước 2 lần lượt là là $67,5 \%$ và $37,5 \%$. Kết quả của chúng tôi cao hơn nghiên cứu của Zhang (2015) với tỉ lệ đáp ứng bước 1 là $57,7 \%$ đồng thời cũng cao hớn nghiên cứu của Chen và cộng sự (2020) với lệ đáp ứng toàn bộ là $49 \%$ trong đó tỉ lệ đáp ứng toàn bộ của điều trị tại bước 1 , bước 2 , và bước 3 lần lượt là 53\%, 26,7\%, 26,7\% [5] [7].

Có sự khác biệt này có thể là bệnh nhân trong nghiên cứu của tác giả Zhang và Chen bao gồm cả nhóm bệnh nhân di căn não, đây là nhóm bệnh nhân có tỉ lệ đáp ứng điều trị kém hơn so với những bệnh nhân có vị trí di căn khác.

Trong nghiên cứu của chúng tôi, thời gian sống thêm không bệnh tiến triển trung bình là 6,97 tháng, ngắn nhất là 3 tháng, dài nhất là 18 tháng. Trung vị sống thêm không tiến triển là 7,0 $\pm 0,5$ tháng. Kết quả của chúng tôi thấp hơn nghiên cứu của Zhang và cộng sự (2015) với PFS là 7,8 tháng [5]. Tương tự, nghiển cứu của Chen và cộng sự 2020 với trung vị PFS là 8,4 tháng [7]. Điều này có thể giải thích do các bệnh nhân trong nghiên cứu của chúng tôi có tỉ lệ di căn tạng lớn hơn, tî lệ di căn xương và tái phát tại chố tại vùng thấp hơn. Đây là một trong những yếu tố tiên lượng xấu ảnh hưởng đến kết quả điều trị.

Đánh giá về độc tính của phác đồ, nghiên cứu của chúng tôi thường gặp chủ yếu là độc tính độ 1, 2. Các độc tính thường gặp là ha bạch cầu hạt $(63,5 \%)$, hạ huyết sắc tố $(50 \%)$, hạ tiểu cầu $(26,8 \%)$, rụng tóc (46,4\%), nôn và buồn nôn (51,7\%).

\section{KẾT LUẬN}

Sự phối hóa chất dựa trên nền tảng platin đem lại hiệu quả về tỉ lệ đáp ứng và thời gian sống thêm bệnh không tiến triển cao cho bệnh nhân UTV BBAT tái phát hoặc di căn. Tuy nhiên cần đánh giá và theo dõi sát độc tính của phác đồ trong quá trình điều trị.

\section{TÀI LIỆU THAM KHẢO}

1. CA: A Cancer Journal for Clinicians. American Cancer Society Journals, $<$ https://acsjournals.onlinelibrary.wiley.com/journa 1/15424863>, accessed: 30/05/2021.

2. Kaya V., Yilldirim M., Yazici G. và cộng sự. (2018). Effectiveness of Platinum-Based Treatment for Triple Negative Metastatic Breast Cancer: a Meta-Analysis. Asian Pac J Cancer Prev APJCP, 19(5), 1169.

3. Brouckaert 0 ., Wildiers H., Floris G. và công sự. (2012). Update on triple-negative breast cancer: prognosis and management strategies. Int J Womens Health, 4, 511-520.

4. Dent R., Trudeau M., Pritchard K.I. và cộng sư. (2007). Triple-negative breast cancer: clinical features and patterns of recurrence. Clin Cancer Res Off J Am Assoc Cancer Res, 13(15 Pt 1), 4429-4434.

5. Zhang J., Fan M., Xie J. và cộng sự. (2015). Chemotherapy of metastatic triple negative breast cancer: Experience of using platinum-based chemotherapy. Oncotarget, 6(40), 43135-43143.

6. Eisenhauer E.A., Therasse P., Bogaerts J. và cộng sự. (2009). New response evaluation criteria in solid tumours: Revised RECIST quideline (version 1.1). Eur J Cancer, 45(2), 228-247.

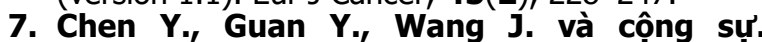
(2020). Platinum-based chemotherapy in advanced triple-negative breast cancer: A multicenter real-world study in China. Int J Cancer, 147(12), 3490-3499.

\section{BÁO CÁO CA BỆNH: HộI CHỨNG EKBOM}

\section{Phùng Thị Thúy Hằng ${ }^{1}$, Lê Việt Sơnn ${ }^{1}$, Nguyễn Thị Thanh Tâm¹, Nguyễn Thị Phương Loan ${ }^{2}$, Vũ Văn Hoài ${ }^{2}$, Nguyễn Thị Phương ${ }^{3}$, Nguyễn Văn Giáp ${ }^{3}$, Phạm Văn Thích ${ }^{3}$, Bùi Văn $\mathrm{San}^{3}$}

\section{TÓM TẮT}

\author{
${ }^{1}$ Bênh viện Bạch Mai \\ ²Viện Sức khoẻ Tâm thần, Bệnh viện Bạch Mai \\ ${ }^{3}$ Đại họ Y Hà Nội \\ Chịu trách nhiệm chính: Bùi Văn San \\ Email: buivansan@hmu.edu.vn \\ Ngày nhận bài: 16.8 .2021 \\ Ngày phản biên khoa hoc: 14.10.2021 \\ Ngày duyệt bài: 25.10 .2021
}

Bệnh nhân nữ 53 tuổi, vào viện vì: Tổn thương mắt - luôn cho rằng có những côn trùng cắn trên da. Bệnh biểu hiện khoảng 03 năm nay, bênh nhân mô tả nhìn thấy "con ghẻ" màu trắng hình dạng như hạt gạo có chân bò khắp người bệnh nhân. Bệnh nhân đi khám, điều trị chuyên khoa Da Liễu nhiều nơi nhưng tình trạng trên không đõ. Khoảng 03 tháng nay bệnh nhân cảm giác con này thường xuyên bò vào tai vào mũi, vào mắt cắn ở trong mắt, bệnh nhân đi khám và điêu trị tại Bệnh viên mắt TW, khoa Mắt Bệnh viện Bạch Mai, được làm xét nghiệm, khám lâm sàng chẩn đoán: viêm củng giác mạc hoại tử - đái tháo đường - 